\title{
Networked Information Resources: The Wave of the Future
}

\author{
by Bil Stahl
}

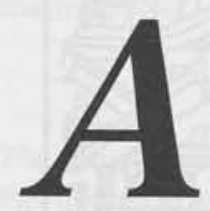

s professionals, librarians have long undervalued their knowledge and skills, or in some cases misplaced them. The bedrock of librarians' knowledge and skill is not in their knowledge of arcane classification systems, or even their ability to organize information per se. Their fundamental value is in being able to identify the value of various types of information resources for the "uninitiated" user. Few librarians work with experts on finding information resources of value directly related to the expert's area of expertise. (I am not talking about locating facts for researchers.) However, what every user needs from the library is help in finding information in areas with which they are not very familiar.

The librarian's knowledge and skill in connecting ordinary people with information are generally not found elsewhere. Library online catalog systems were one of the first, and still are one of the few, systems designed to be used by large numbers of non-specialists on an infrequent basis. With technological advancements, the expectations of society have risen, and many system developers, database managers, and other system administrators are faced with supporting the "library-type" user. They are looking for help and guidance. A few have identified the library profession as a source for this help. Others do not know where to go. Librarians ignore this opportunity to step forward to fill this role at the risk of their future.

Telecommunications has significantly heightened the concern over the "information explosion." The growth of the Internet, which interconnects over 750,000 systems, is occurring at the rate of more than ten resources added daily. A major concern among the users of the Internet is how to keep track of all of these resources and be knowledgeable about their content. The Coalition for Network Information (CNI), which is made up primarily of library and computing professionals, is addressing this problem, but its resolution will require significantly more effort on the part of the library community. However, many librarians despair because libraries do not "own" these network resources, and they do not fit into our classification systems and service models. This despair is a waste of energy because it is apparent that libraries will no longer "own" significant numbers of the available information resources that people will routinely use. We will never have a single organizational system that can effectively accommodate the uncontrolled growth of network information sources in any acceptable or timely manner. Librarians must stop slavishly trying to protect their old modes of operations and aggressively seek ways to blend the appropriate mix of old and new operations. Wealso must develop thenecessary processes to changethis blend within days and weeks, rather than months and years.

Libraries must budget significant amounts of time and money for understanding the new resources, and the means of accessing them, that telecommunications technology has made possible. Then librarians must incorporate them into their menu of offerings to their clientele. This means that adequate equipment and telecommunications services must be acquired even at the expense of collections, the library's whole concept of collection development must change to "access development," and the scope of "BI" must broaden greatly.

While I am not suggesting the demise of the library as we know it today, our current model will account for less and less of the significant value of future libraries. Nor am I suggesting that each library must individually solve all of the problems that these new network information resources pose. Libraries have a strong and successful tradition of benefiting from collective efforts. What Iam strongly recommending is that every library invest this year in the technology to provide general access to networked information resources by the reference staff and by the users of reference departments, and that these resources become part of reference services. This might require tracking down the people in your parent organization who are responsible for telecommunications and selling them on the importance of providing sufficient, not token, connectivity to the "outside" world. This will also require library staff to understand adequately concepts such as TCP/IP, TELNET and File Transfer Protocol (FTP).

Professionals are urgently needed to deal with the exploding amount of electronic information becoming available. This need must and will be met. At this juncture, it is up to us to decide if librarians will be the ones to fill the need. We will not be at this juncture long. By not deciding and not taking action soon, we will in fact have made the choice to pass our role on to someone else. 


\title{
Counter Point
}

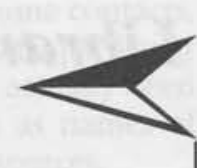

\section{I'm Sorry, All Circuits Are Busy Now}

\author{
by Harry Tuchmayer, Column Editor
}

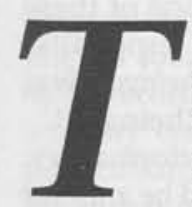

here is something terribly wrong out there. I don't know exactly what it is, but I suspect it has something to do with the fact that an average individual can't even use a telephone without getting some instruction. Thus, when I read all these wonderful articles about the vital role telecommunications will play in managing the information explosion, I am reminded about all those ads that I remember as a kid which glorified chemicals and plastics as the solution to modern life. As we now know, this revolution in our daily lives came with a heavy price - pollution. Are we now at that same point with telecommunications? Have we reached information overload?

As far as I can see, telecommunications isn't solving the problem; it's merely attempting to manage the mess. Sure, all these networks and information services sprouting up all over are causing us to rethink the way we do business, but should they? Are we to become slaves to this new industry? Are we supposed to throw away our Harlequin romances and cancel our subscriptions to newspapers in order to provide access to the multitude of information gougers?

I know I probably sound hysterical, but I'm not so sure I like the direction we are headed. I for one actually like paper, and I think most other people do, too. While I agree with Bil that we must "... aggressively seek ways to blend the appropriate mix of old and new operations," I can't believe we must invest heavily in this technology. How many indexes and how many services are enough? We seriously need to look at our mission and decide just how many indexes are needed to augment our collections, but let's not lose sight of our objectives, and let's remember who our clients are. We need to help them sift through the mess of information, not overwhelm them with sources.

Perhaps it all boils down to just how much information is enough, and who is to decide. But really, folks, do we actually need 750,000 systems, growing at a rate that would put rabbits to shame? As everyone tries to cash in on this information madness, isn't it our responsibility to be a little bit more selective? After all, do you buy every new reference source that comes out, or make it your mission to purchase every title regardless of its review?

Rather than applaud this madness, shouldn't we put a stop to it? The Coalition for Network Information needs to do a lot more than merely keep track of and be knowledgeable about these resources. They need to inform the consumer about the unnecessary duplication and needless proliferation

Perhap it all boils down to just how much information is enough, and who is to decide.

- Tuchmayer

\section{While I am not suggesting the demise of the library as we know it today, our current model will account for less and less of the significant value of future libraries.} of databases, networks, and bulletin boards. Quality, not quantity, used to be a motto many libraries lived by. And while I'm not suggesting a return to those days, I am calling for a halt to the unquestioning belief that somehow this is all a good thing.

There is a silver lining. The growth of the telecommunications industry has made it painfully clear that it is time to reevaluate the whole concept of collection development. The revolution in the information industry goes far beyond the world of telecommunications; it has affected publishing and consumer attitudes about information access. Clearly, these are issues of great importance to us, and we have waited too long in considering their impact. Also, as Bil says, we need to become more knowledgeable about such concepts as File Transfer Protocol, TCP/IP and the like. Librarians cannot afford to let the high tech world of telecommunications pass them by. After all, our patrons depend on us to interpret these resources and expect us to help them through this maze of information choices.

But let's not all jump on the band wagon at once. I know that while my kids are always interested in playing with the latest toy, they often return to their old favorites. More often than once, they've discovered that this glitzy new toy is not all its cracked up to be. And even when they have discovered something new, they still can play with only one toy at a time. 